\title{
Article
}

\section{A Tardy Uptake}

\author{
Anne Freadman \\ University of Melbourne
}

\section{Introduction}

Following Carolyn Miller's (1984) definition of genre as social action, subsequent work in the field of rhetorical genre theory has focused on two aspects of her account. The first is the claim that "a genre is a rhetorical means for mediating private intention and social exigence" (Miller, 1984, p. 163). The site of this mediation is now referred to as the subject-a term that is imported from psychoanalysis and critical social theory. I am concerned that the theoretical freight carried by this term-with its claim to address the "big questions" of subjectivity-diverts us from our focus on "how the genre works as rhetorical action" (Miller, 1984, p. 159). I shall replace the subject with the agent, moving then to argue that bringing uptake to bear on agency helps shift the debate to a more strictly rhetorical terrain. ${ }^{1}$ The second aspect that has been focused on is exigence: the "social motive" of rhetorical action, "an objectified social need" lying at "the core of situation" (Miller, 1984, pp. 158, 157). I consider an ambiguity at the heart of this concept of exigence between the work it does in accounting for punctual rhetorical action-the genre in actuand its work in generalizing over some genre in virtu. Because of this, I move to replace exigence with alternative ways of conceiving the site of rhetorical action. Throughout, I accept broadly the framework of Rhetorical Genre Studies. While I seek to solve the problems through a rigorous reliance on rhetoric, I move beyond this frame when I discuss the restrictions on a theory of genre imposed by an exclusive assumption of verbal or discursive acts.

\section{Preliminaries: On Genre and Genre Theory}

\section{The principle of difference}

This principle holds that there is never one genre without another, with which it stands in a relation of reciprocal difference.

\footnotetext{
1 I first introduced this term in Freadman (2002).
} 
1a. The general term genre is intelligible only in terms of the principle of difference. It does not designate the foundation of the open set of genres, nor does it generalize over that set. It is an extrapolation, an abstraction, posited as the object of a meta-genre.

1b. In the light of 1a, genre does not designate a predictive set of criteria for what does, and does not, count as a genre. It is simply a site at which converge a number of issues in the analysis of discourse. Not all these issues would necessarily come into play in any particular genre. Those that do set out the requirements on a description of that genre.

1c. Studies of genre, or genre theory, are a genre, or a field, or a set, of genres. Pace Russell (Irvine \& Deutsch, 2016), this genre is a member of the set it theorizes. As a first approximation, let us say that the aims of any such study are to inquire into the criteria upon which we differentiate one genre from another, where "we" designates the community of users.

1d. I shall use the term genre studies to denote a descriptive enterprise; their typical procedure is that of the case study. On the other hand, genre theory often comprises critical analysis of theoretical concepts or issues; it typically uses quoted material from a variety of genres, using this material to exemplify or illustrate its propositions, or to problematize theoretical concepts drawn from elsewhere. The present paper may count as an exercise in theory on these grounds.

Some genre theory pursues an explanatory objective. Thus, for example, work on the genres of new media might seek to explain the emergence of new genres in terms of the media that have become available. Likewise, the emergence of new genres might be explained in terms of functional criteria: a new genre might appear to answer a new need, or to fulfil a new function. On the basis of a study of blogs, for example, Carolyn Miller asks where genres come from; to answer this question, she posits a "previously unrecognized, or inchoate, shared rhetorical exigence" (Miller, 2017, p. 2). It should go without saying that this distinction between studies and theory is not rigid, and that some work combines aspects of the two.

\section{Rhetorical Genre Studies}

Rhetorical Genre Studies, or their theory, restrict the scope of their inquiry to the field of rhetoric, conceived both as an account of the social action of discourse and as the art, or practice, of discourse to carry out such action. It is consistent with this restriction that they seek criteria that would differentiate between genres on the grounds of the actions they carry out, and the ways and means of that carrying out. These are functional criteria. 
2a. Mutatis mutandis, Rhetorical Genre Studies can extend their scope beyond the field of discourse stricto sensu. Under this extension, discourse is considered as one semiotic medium among many, and rhetorical action is understood as carried out potentially in any semiotic medium (painting, photography, film, music, dance, etc.). The advantage of this extension is that it frees the account to comprise the interaction of the various semiotic media involved in any genre. For example:

- Self-evidently, film edits together several semiotic media: music, moving photography, music, voice, bodily movement, etc.

- Written discourse is a visual medium, with language displayed in handwriting, font, layout, etc.

- Spoken discourse is an aural medium, with language proffered in voice tone, rhythm, pace, volume, etc. In ancient accounts of oratory, this range comes under "delivery," and involves gestures.

- The visual practices of painting, photography, sculpture, etc. are taken together with the verbal practices of titling, and with placement (curatorial practices).

- Books are not merely texts, but physical objects presented visually in electronic or paper-based materialities, and arranged in a sequence of genres, often differentiated by font, layout, and formal discursive conventions (lexicon, tense, syntax, etc.).

2b. Taken as an account of the practice, or art, of the genres they consider, Rhetorical Genre Studies stand or fall by the adequacy of their descriptions in terms of specifiable objectives. These objectives are frequently set by professional and institutional uses of genre studies. For example, writing and composition studies, including applied linguistics and the teaching of English as a second or professional language, require this meta-genre for pedagogical purposes (curriculum design, instructional strategies, testing, etc.).

\section{Genre theory taken as a genre}

Bis 1c: "Genre theory is a genre, or a set of genres. Pace Russell, it is a member of the set of its objects." Genre theory cannot transcend this condition. Under the premises of rhetorical genre theory, it performs specifiable social actions.

Any rhetorical action is situated socially, historically, culturally, and locally; this being the case, so are the genres of rhetorical genre theory. 
3a. It follows from the material situatedness of generic practices that they are modified over time and occasion. The art is responsive to the situation in which it arises.

3b. Rhetorical genre theory presupposes the historical condition of its objects. It neither stabilizes them, nor seeks to stabilize itself. It is therefore not a theory in the sense of speculation; it does not dictate practice, and it fails spectacularly to predict the next thing. It consists only, but importantly, as ongoing, interminable, reflection upon practice.

3c. Like any genre, therefore, it has a past upon which it draws and that it seeks to amend, correct, or improve upon in light of the present in which it is practised. Its future is short, "stabilized-for-now" (Schryer, 1993, p. 200)² and its ambition modest (3b).

\section{Social action}

Rhetorical Genre Theory differentiates its objects on the grounds of the actions they are used to perform (see $2 \mathrm{~b}$ ). Rhetorical theories of genre should do more than presuppose "social action"; they must spell out what is meant by "social" and by "action," and hence on the constraining and motivating conditions operating on the actions performed.

4a. Two dimensions of these conditions have attracted particular attention in recent work. These are the perpetrator of the action, and the situation of that action. ${ }^{3}$

(i) What account of the perpetrator-the subject—of those actions would be both adequate and fit for purpose?

(ii) How do we conceive of the social situation that commands rhetorical action? Provisionally adopting the term launched by Lloyd Bitzer (1968) and adapted to genre theory by Miller (1984), this is exigence.

(iii) What are the consequences of bringing uptake to bear on 4a (i) and (ii)?

The present paper will address these questions.

\footnotetext{
${ }^{2}$ Schryer (1993) redefines genre as "a stabilized-for-now or stabilized-enough site of social and ideological action" (p. 200). She requotes this formulation in later work (Schryer, 2018, p. 154).

${ }^{3}$ Evidently, other topics have also attracted scholarly attention: I note in particular media, including the new media, and mixity.
} 
Volume 30, 2020

http://journals.sfu.ca/cjsdw

\section{The Subject}

Setting aside its use in grammar and related areas, the term the subject is philosophically recent, appearing first in phenomenological accounts of the apprehension of intentional objects. More relevantly to its adoption in genre theory, it has been used as a replacement for the self, which has been problematized, notably in feminist philosophy, drawing on an integration of psychoanalytical theory and critical social theory. In this sense, the term derives from two quite different, if not contradictory, ways of thinking about persons in society. The first is that under the presuppositions of a strictly hierarchical-say, feudal-society, a person is "subject to" a higher authority, ultimately the sovereign; under democratic regimes presupposing equality, we are citizens, not subjects, who can change the government and are not "subjected to" it. However, the old sense of the term persists: one can be subjected to violence and torture, as well as to the mechanisms of power available to the society of which one is a member. To be subject in this sense is to lack autonomy and freedom of action; it is to be acted on. The second sense of being a subject derives from the phenomenological tradition: it is to be the opposite of an object, and hence, to be the source of consciousness and will. Is the self "subjected" or is it a "subject"? Hegel-a key influence in mid-twentieth-century continental philosophy-articulated the master-slave dialectic in this tradition, showing a subject defined by its power to subject. Drawing on this dialectic, Simone de Beauvoir's The Second Sex-to select only this iconic treatise as an example-is both an account of the subjection of women to the authority and power of men, and a contestation of this subjection in terms of an anti-essentialist account of the gendered self: "Other" to the subject, she is "the non-subject, the non-person, the non-agent" (Willett, Anderson, \& Meyers, 2015), occupying the Hegelian slave-position.

To simplify the evolution of a very complex philosophico-political quest, we might say that (Western) feminism has moved from being a struggle against subjection towards developing an account of gendered selfhood: the female, or feminine, subject. In this, it has lain at the heart of farther-reaching accounts of subjectivity not limited to the struggle for women's rights or to the interests of one gender. In these accounts, the subject is understood as both "subject to" social forces and as the "subject of" action, ${ }^{4}$ the former both mediating and constraining the latter, the latter understood as the site of desires and drives. It is in this sense that subjectivity has emerged as a significant issue in genre theory. What theoretical account of the subject would be both

\footnotetext{
${ }^{4}$ See Willett et al. (2015) for a clear account of the critique to which the Kantian subject has been subject in order to achieve this synthesis: "as valuable as rational analysis and free choice undoubtedly are, feminists argue that these capacities do not operate apart from affective, biosocial, socio-economic and other heterogeneous forces that orchestrate the multilayered phenomenon that we call the self."
} 
http://journals.sfu.ca/cjsdw

adequate and fit for the purpose of analysing the subject of genre taken as social action? The question is particularly pointed in the teaching of writing: if any genre is considered to be a formula, writing well is nothing more than conformity; there is no room for invention or creativity, no room for greater or less rhetorical effectivity. Yet the very basis of rhetoric is the assumption that the rhetor can modify the situation on which she seeks to act. What does, or can, the subject do?

The simple answer to my question is: "the subject practises the genre." I argued this in a recent paper called "Where is the Subject?" in which I studied a literary essay by Helen Garner (Freadman, 2014). ${ }^{5}$ Yet my adoption of the term subject in that paper makes me uneasy, and here I want to displace it. Used non-technically, the notion of the subject is all too often mortgaged to the notion of an originating, self-possessed source of invention (See Miller, 2007, p. 143), and the technical concept has been used to dismantle this assumption: theories of subjectivity seek to explain the emergence of a subject from the intersection of power and desire. This question, I suggest, has no pertinence in studies of genre. How a subject comes to be is a question concerning authorship, a concept attracting sophisticated revision at the hands of feminist literary criticism (e.g., N. K. Miller, 1988). It—and the assumptions underpinning the concept of subjectivity-are at odds with the assumptions and purpose of rhetorical theory, which needs only an agent. Agency, writes Carolyn Miller (2007), "must be a property of the rhetorical event or performance itself. [...] [It is] positioned exactly between the agent's capacity and the effect on an audience" (p. 147). Miller (2001) reminds us that Aristotle makes "ethos integral to rhetorical action" (p. 269) and one of the factors in persuasion. Ethos is the product of ethopoeia, "the construction-or simulation-of character in discourse" (p. 269). It does not depend on prior reputation, but on "performance" (p. 269; this position is similar to that spelled out by Goffman, 1959). A fortiori, an account of agency does not require the excavation by psychoanalysis of the wellsprings of Romantic accounts of personality or of creativity.

The theoretical difficulties associated with concepts of subjectivity have been handled in various ways by workers in Rhetorical Genre Studies. Fuller and Lee (2002) - who retain the term subject for reasons inherent in the social theory they adopt-acknowledge the need to

disrupt the tendency to take the question of the "subject" of a generic utterance as given, as already fully formed prior to the utterance. [They] seek instead to ask questions of the effectivity of genre in the formation and positioning, the "displacement" and "replacement" of the subject within complex relations of power and desire. (p. 212)

\footnotetext{
${ }^{5}$ I thank Anthony Paré for the problem he put to me when I presented that paper; his disquiet nudged me into the reflections I present here.
} 
Volume 30, 2020

http://journals.sfu.ca/cjsdw

This move places genre within these relations-indeed, making genre one of the social forces that explain the provisional formation of subjectivity-and serves to handle the pedagogical difficulties raised by a mismatch between the student's desires and frustrations and the requirements of the genre. Likewise, Anthony Paré (2002) seeks to handle a comparable mismatch between the professional persona required of social workers for certain genres of reporting, and the cultural inhibitions and protocols of their position vis-à-vis their clients. Unlike Fuller and Lee, he does not adopt the terminology of the subject, or its theorization by postmodern accounts of power and desire, but instead uses the more familiar terminology of ideology and identity.

Equally wary of the term subject and preferring agency (adapted here from Burke), Anis Bawarshi (2003) shifts the focus of his work "from the text and toward the writer" (p. 54), then extends agency outwards: the writer "participates within a larger discursive and ideological agency" (p. 60). Insofar as they are an agent of the genre, the writer colludes with the structures of power that genre enacts. In this shift, Bawarshi follows Bazerman, whose work he cites in an epigraph: "Genres, in-so-far as they identify a repertoire of possible actions that may be taken in a set of circumstances, identify the possible intentions one may have" (p. 49). There is no desire here, but Miller (1984), I recall, claims that "a genre is a rhetorical means for mediating private intentions and social exigence; it motivates by connecting the private with the public, the singular with the recurrent" (p. 163).

We might note that most of these accounts of the subject of writing take for granted that the site of the problem is the writer or speaker. This derives from the professional preoccupations of the researchers, all teachers of writing and composition or rhetoric, and all concerned with equipping their students with the professional competence needed for their practice as individual professional workers. The focus is therefore on one partner in the communicative event. The exception to this generalization is Miller (2001), who shifts her attention to "the mysteries of trust and character at the interface of human interaction" (p. 255). Elsewhere she stresses the importance of audience, notably arguing that "agency must be not only a capacity of the rhetor but also in some way a capacity of the audience" (Miller, 2007, p. 145). The question implied by "in some way" is answered later in her argument: "There are at least two subjects within a rhetorical situation, and it is their interaction, through attributions they make about each other and understand each other to be making, that we constitute as agency" (Miller, 2007, p. 150).

Miller's formulation implies a distinction between subjectivity and agency, with the term subject referring to an individual participant, and agency referring to what makes the genre work. I am not sure that we need a theory of the individual participant in genre theory, and certainly not of a subject motivated by the forces of the unconscious. I suggest that the very use of the term the subject implies these forces, and that they cannot account for a rhetorical agent's capacity for 
http://journals.sfu.ca/cjsdw

action in situation. Subjectivity may be useful to the teacher whose concerns with the institutional powers mediated by the classroom meet the pastoral care she owes to her students, but this is a different matter from theorizing genre, and from studying or teaching a genre. To teach a genre (see below) is to teach a collection of rhetorical skills.

Subjectivity and agency do not cover the same terrain; nor are they complementary. Indeed, politically or ethically they may conflict: are we concerned with the creative liberation of the self, or with the pragmatics of social action? At bottom, I believe that psychoanalysis and genre theory are incompatible, the former recognizing only the difference between fiction and (the impossibility of representing) fact, the latter taking as its object the multiplicity of genres and their social stakes. I choose to use agency, taking it to be a matter of the interactions of two agents, leaving out of the equation the ambitions-ambiguities? impasses?-of theories of subjectivity. This brings me to uptake.

\section{Uptake}

So I ask now, what the agent does.

She plays tennis. I first used this analogy as a way of suggesting that we do not exchange fullyformed meanings, but "shots" in a game (Freadman, 1987/1994); in my work on uptake, I have extended this idea to genre, arguing that the genre of an utterance is only provisional, and is inflected and indeed modified by the way it is taken up (Freadman, 2002). The intention, mediated though it be by social forms and forces, is not locked in place, but is subject to a feedback loop whereby it becomes what it will have been through the dynamics of communicative interaction. ${ }^{6}$

While the term is borrowed from Austin, uptake is an uptake of the work of Mikhail Bakhtin, one aspect of whose work is a critique of formal linguistics. Where linguistics studies the formal units of language taken as a system-words or phonemes, morphemes, and the syntactic strings they form-Bakhtin's focus is the utterance, the unit of speech in dynamic social settings. This focus entails repudiating the "fiction" of the "passive listener" (Bakhtin, 1986, p. 68). As he writes:

Any understanding of live speech, a live utterance, is inherently responsive. [...] The speaker himself [...] does not expect passive understanding that, so to speak, only duplicates his own idea in someone else's mind. Rather, he expects response, agreement, sympathy, objection, execution, and so forth (various speech genres presuppose various integral orientations and speech plans on the part of speakers or writers). (Bakhtin, 1986, pp. 68-69)

Formal linguistics presupposes a model of speech exchange quite inadequate to what happens in

\footnotetext{
${ }^{6}$ For an elaboration of uptake somewhat different from the one I present here, see Bawarshi (2015).
} 
"living speech." We might think back to Saussure's diagram of parole, where the output of the speaker is matched in the mind of the listener, and the "dictionary" informing the former is matched by an identical dictionary in the latter. The "abstractions" of formal linguistics weaken "the link between language and life"; "after all, language enters life through concrete utterances . .. and life enters language through concrete utterances as well” (Bakhtin, 1986, p. 63). As Bakhtin writes:

The desire to make one's speech understood is only an abstract aspect of the speaker's concrete and total speech plan. Moreover, any speaker is himself a respondent to a greater or lesser degree. He is not, after all, the first speaker, the one who disturbs the eternal silence of the universe. And he presupposes not only the existence of the language system he is using, but also the existence of preceding utterances. [...] Any utterance is a link in a very complexly organized chain of other utterances. (p. 69)

What is the place of genre in this account? Utterances are cast in "relatively stable types," or "genres" which are developed by the "spheres" in which language is used (Bakhtin, 1986, p. 61). Bakhtin (1986) presumes that all responsive chains take place within one such sphere (p. 91) and does not consider the possibility of an alternative scenario. Notwithstanding this, each utterance "is filled with various kinds of responsive reactions to other utterances within the given sphere of speech communication" (p. 91). This is because the sphere, the chain, and the preceding utterance do not entirely determine what comes next: there is reinterpretation and "struggle" (p. 92).

So it is that we might conceptualize what happens in a tennis match: the making of a shot depends not just on reception of the previous shot, but on the (re)interpretation of the opportunities it offers and the player's struggle with its challenges and constraints: speed, position, direction, and spin. To return a ball is to read such things, and to calibrate one's tactics accordingly. To learn to do so is to acquire a skill which is governed by the rules of the game, but which cannot be adequately described by those rules. For this, we do not need to invoke subjectivity, with its inevitable appeals to interiority. ${ }^{7}$ Agency is inter-actional.

Now, if it is the case that no speaker "disturbs the eternal silence of the universe," then we need to think about how starting starts. What does the agent take up when she apparently initiates an exchange? Bakhtin's strictures concerning the distinction between the abstract language system and the utterances that constitute the responsive chain of previous and subsequent utterances do not merely pertain to speech; they have a clear implication for writing, and for learning to write. As he writes: "Everything we have said here also pertains to written and read speech,

\footnotetext{
${ }^{7}$ To invoke a recent example from championship tennis: in the notorious case of Nick Kygrios, the expression and display of interior states counts as a rule violation, a loss of decorum.
} 
with the appropriate adjustments and additions" required for the "delayed" response imposed by such forms (Bakhtin, 1986, p. 69). He later describes that "however monological the utterance may be (for example, a scientific or philosophical treatise) ... it cannot but be, in some measure, a response to what has already been said about the given topic, on the given issue" (Bakhtin, 1986, p. 92). The "rules of the game" in this case are given by the rhetoric of the discipline, as well as by institutional parameters. The skills one learns in learning to write are these: we begin with our uptake of the possibilities and opportunities we are faced with, and we plan our discourse in terms of the possible responses it may elicit, attempting to restrict their unpredictability as much as possible and, indeed, to constrain them.

It is time for some illustrations. I will adapt Bakhtin's account, using the term uptake for three points of the responsive chain: (i) the speaker or writer occupies the receiver's position in a conversation; (ii) in what Bakhtin calls the speaker's plan, a calculation is made concerning possible uptakes by a potential receiver; (iii) the speaker initiates a conversation. To develop these points, I plunder a collection of essays by Maria Tumarkin (2018) for examples of each respectively. The first will show how the writer takes up opportunities from the occasions provided by conversations. The second will show Tumarkin calculating the uptake she intends to elicit from her readers. If writing is rhetorical, then all writing does this pervasively, rendering it potentially artificial to extract particular quotations to show this calculation. For this reason, I will restrict my choice to writing where the calculation is explicit. The third will show that the very conception of the essay is an uptake. The first and third are not strictly different, but it is useful to separate them. The first shows uptake in action in the responsive chains that make up conversations; this is Bakhtin's principal focus. The second shows rhetoric at work on what might come next, attempting to determine the range of possibilities of the return shot. And the third shows the generation of the creative impulse by a "found object" in the universe of discourse.

\section{Example 1:}

At Bryn's school, Stephen, a year 10 boy, killed himself years before Bryn's suicide. [...] Amanda was there when the principal, dead now, gathered the year 10s and said "it's self-centred and indulgent of you to grieve. Think about Stephen's parents. [...]"

Back in the classroom she spoke. "This is not my place but I must tell you-of course you feel. You have every right to feel." She went up to the principal, said it was wrong what he had said. How that old principal hated her guts. Later he'd get rid of her but this once he couldn't deny her. He regathered the year 10s. Said "I made a mistake." Feelings were allowed. (Tumarkin, 2018, pp. 15-16) 
The passage is quoted from the first essay of the collection. The whole of this essay is devoted to adolescent suicides and their aftermath. At the head of the quoted sequence, a schoolboy has committed suicide; two contrasting reactions, that of the principal and that of the teacher, are in conflict over what to say to his fellow students regarding this event. We are told that there is a "place" to speak: that place is a function of the authority of the head teacher, presumably in the formal setting of an assembly hall. "Back in the classroom" is the place of the subordinate teacher, Amanda. There, it is not her place to make her view known to her pupils. When she intervenes, she does so in order to contest the rule against emotion enunciated by the principal. If his discourse is a moralizing one, hers takes on the pastoral role; she addresses the subjectivity of the young people, concerned as she is with the lived experience of the students: "You have every right to feel." She is breaking decorum-governed by the rules of the institution-and she will be duly punished. Note that both speeches, the principal's and the teacher's, are uptakes of the same event, and that the subordinate teacher's is also an uptake of her superior's. Both are attempts to direct the uptake of the students; Amanda's "allows them to feel."

As in overhearing, the writer has no place in this conversation. We learn elsewhere in the essay that it has been reported to her by Amanda in a conversation, and it is this later conversation that she takes up. She does so not only to take sides, but to place this case in a series through which she reflects on authority and the institutional control of uptake. I cannot pursue this dimension of the issue here. Suffice it to say that it raises again the conflict of power and desire mentioned earlier, again - significantly-in a pedagogical setting, where what is at stake is the control of the place of speech and how it is appropriately used. Both the principal and the teacher are "managing" the students' response to the suicide. The responses listed by Bakhtin-agreement, sympathy, objection, execution, and so forth-are null when the students are faced with the principal's prohibition, and while Amanda does respond with direct contestation, she too is silenced when the principal fires her-that is, divests her even of her legitimate place in the classroom. Uptake depends on occupying a place in the responsive chain; it is not automatic, and it is not, I think, primarily a matter of subjectivity. In the quoted passage, Tumarkin responds to a private conversation by reporting it, hence starting a new chain and aiming to secure public uptake.

In my next example, we will see Tumarkin explicitly directing the uptake of her readers. The topic is provided by the story of a Jewish woman protected by a Polish family under the Nazi occupation; she is hidden in a potato pit with her mother and a baby son. However, she is captured, taken to Auschwitz, then survives and immigrates to Australia with her son; many years later she is charged with abducting her grandson by hiding him in a way that repeats the refuge she had been given to elude the Gestapo. Two families and three generations are mentioned in 
this story: "the woman" refers to the person who immigrates to Australia following the events reported; she has a mother and a son. The person hiding her is a "lady doctor" who also has a son; this son marries "the woman" and immigrates with her. The doctor has an anti-Semitic husband, briefly mentioned at the end.

\section{Example 2:}

To be born in the worst of times imaginable, what does that leave you with? And then to survive? The [lady] doctor hiding them had to go away for a few days and the woman's mother decided that the potato pit was no longer safe, so they climbed up. They were caught and sent to Auschwitz but by then the war was ending, the baby was a toddler, and even though people were still being gassed the mother and the daughter sneaked out. The woman married one of the doctor's sons. In time, the woman, her husband, their young son and the woman's mother left Poland. Too much blood was spilt in Poland, too much hatred could not be erased, and the anti-Semitism was unrelenting. The in-laws were deeply anti-Semitic too: the lady doctor, the saintly rescuer, turned out to be as bad as her husband, who openly and feverishly hated Jews. (That's a little side-parable for those who think wars are over when they appear to be over. Or that people pick their sides and stay on them. Or that we become our parents. The lady doctor's son who married the woman did not become his mum or dad.) (Tumarkin, 2018, p. 69)

The story relates the reactions of the local Polish population to the circumstances, taking care to show the paradoxical, even contradictory, motivations of people who, although anti-Semitic, saved Jews from deportation to Auschwitz. Their uptake of the woman's situation may be governed by compassion, while their uptake of the ambient discourse is exactly what that discourse intends it to be. Beyond this, however, I wish to focus on the parenthesis at the end, and particularly on the fact that it is a parenthesis. The device allows the insertion of an authorial voice into the narrative in much the same way as the moral is made explicit in old-fashioned children's stories, or in fables. This moral instructs us how to read the narrative. First it specifies the genre: it is a "parable." This is not idle storytelling. It is addressed to us- "those," "we"-as people who read with predictable interpretive frames. We would be wrong to read the story according to these presuppositions: war is not over with the signing of a peace treaty or the capitulation of the enemy-it has an aftermath, like survival. We would be wrong to suppose that people do not have contradictory attitudes, that they "pick their sides" and stay on them: any such frame for making moral judgments relies on a black and white simplification of moral ambiguity. And "we do not become our parents": choice is exercised. I make the same point regarding genre: it is not the case 
that the rhetorical situation in which we find ourselves determines the genre in which we choose to speak; at most it restricts the range of the appropriate conditions governing that choice. Let us note that just as the parentheses signal the end of explicit authorial guidance, so does the specification of the genre tell us the appropriate kind of interpretation of what we have just been told. This includes heading off the potential for asking for more narrative details regarding the husband: all we need to know is that his behaviour did not fit our expectations.

Tumarkin's book is entitled Axiomatic. In English, we say "it's axiomatic," meaning that there is a general truth, crystallized in an axiom, that applies so readily to something that the meaning of this something is self-evident and irrefutable. The titles of the essays are all axioms, some of which are slightly modified: "time heals all wounds," "those who forget the past are condemned to re...," "history repeats itself," "give me a child before the age of seven and I will show you the woman," "you can't enter the same river twice." The essays interrogate these axioms, showing them to be inapplicable to the stories to which they are applied. They are not, in fact, axiomatic.

These axioms serve as titles, and as a point of departure for the writing. Each essay is an uptake of the axiom that generates the reflections. In the rhetoric of the essay, then, the stories are cases against which to test the axioms. My third example shows this procedure. In it, Tumarkin reflects upon the use of a well-known saying, rejecting its claim to represent received wisdom and general truth:

\section{Example 3:}

It's said Jesuits first said "give me a child before the age of seven and I'll show you the man" and this, as all things Jesuit tend to, carries queasy-making undertones of an institution sucking up a child and spewing up a complete, morally delineated being. Education, indoctrination, values inculcation etc.-that's a caricature mostly, an unthinking bit of Jesuit-creaming, besides writer Barry Lopez said it was his Jesuit teachers who woke in him a "capacity for metaphor," also it appears the axiom may have been widely misinterpreted anyway. (Tumarkin, 2018, p. 141)

In this passage, she directs her attention to the very genre of what she has just written: her generalization about the Jesuits is not to be taken seriously as a judgment. Instead, it's a "caricature"- "mostly" - a "bit of creaming," "unthinking," and in any case to be tempered by a more positive judgment concerning the gift of this teaching order to a fellow writer, who credits them with his "capacity for metaphor." Understanding metaphor allows us not to take things literally, it opens up the space of interpretation, and this reflection brings the writer back to the realization 
that the axiom itself may have been misinterpreted. Not an axiom, then, but a proverb-perhaps metaphorical, its applicability subject to interpretation both of the proposition and of the case.

"Never mind," she concludes, "I intend leaving the Jesuits in peace" (Tumarkin, 2018, p. 141). She does so because she grew up in the Soviet Union, so she never heard of the Jesuits "and their axioms" (p. 141). "Writing of herself that she "hang[s] low and loose in the air like an unmanned hot air blimp' and that this is the 'axiom's god-free version', she then introduces a new case and explicates the problem underlying the axiom: 'the seven bit stuck' and the question is whether by that age 'something is constructed that is hard to get at and dismantle or overwrite afterwards" (p.142). Is there a nub of truth independent of the culture in which the axiom is taken as received wisdom? To find out, Tumarkin takes it out of its institutional setting, then pursues the question that arises from it: are we determined by something that marks our birth, or by our experiences? The cases she adduces do not answer the question so much as show its complexity. This too is uptake; it interprets, and one way of doing so is to stop axioms from acting as axioms, stop them from providing easy or automatic answers, and take them as the site of questioning. There are no "consoling pieties," as Helen Elliott (2018) has written about this collection.

Tumarkin is known for her view that there is more to writing than telling stories. The stories in these essays do not stand by themselves for their sentimental hold on our understanding. And uptake is more than taking the next place in the responsive chain. I have given three examples, in all of which "receiving" is far from being an adequate account. In the first, the receiver takes up what has just been said, and uses it to start a new conversation; evident in the second are the writer's strategies for directing the uptake of her reader. And in the third, uptake of a saying is shown to generate the rhetoric of the writing, its use of stories as cases and the dialectical process that reaches no resolution.

I have brought uptake to bear on the question of the subject. I do so firstly to support my claim that subjectivity is not a helpful notion in the theorizing of genre if genre is to be taken as a fully rhetorical way of thinking about discourse. The skill of the rhetor is trained, learned, and performed; while I do not deny the existence of interior states and personal qualities, these cannot account for what the agent does as a rhetor (although they may undermine it). In the case study reported by Fuller and Lee (2002), where the student's subjectivity enters into conflict with the demands of the genre, the conflict is better analyzed as a conflict between two pedagogies, one focused on the acquisition of appropriate, strategic and tactical skills to be used in a performance, the other focused on the backstage person. If we import subjectivity into genre theory, we allow the inner being of the experiential learner to override her meta-understanding of genre as a fully rhetorical practice. Or rather, as I have argued in this section, uptake displaces the site of agency: the dynamics of uptake is that whereby we take a place, or make one, or open the space of 
Volume 30, 2020

http://journals.sfu.ca/cjsdw

questions and interpretation.

I turn now to exigence, the term used in rhetorical genre theory to designate the "place" that motivates speech. In the light of my discussion of uptake, this place is far from static.

\section{Exigence}

The original use of the term exigence cited by Carolyn Miller (1984) is by Lloyd Bitzer (1968) in "The Rhetorical Situation." Bitzer restricts his account to strictly defined "rhetorical discourse," distinguishing it from "non-rhetorical" discourse and "other types" such as scientific, poetic, and philosophical discourse (p. 3); his examples-apart from the fishing example that he cites from Malinowski-are all instances of political speeches. An exigence is that dimension of a rhetorical situation that "strongly invites action" (p. 5). Some other words he chooses besides "invite" are "oblige" and "dictate"; an exigence is an "imperative stimulus" to speech (p. 5.), and "an exigence is an imperfection, marked by an urgency; it is a defect, an obstacle, something waiting to be done, a thing which is other than it should be" (p. 6). The range of these verbs shows an inclination on Bitzer's part to extend the notion beyond the genre of political speeches, and Miller's adaptation of it is intended explicitly to apply it to any and all genres.

I want to note two facts about Bitzer's use of exigence. The first is that it does not refer to genre, and the second, following from this, is that an exigence appears in his work to be local: a speech is given for a particular purpose to achieve a particular outcome. Miller (1984) adapts it for the purpose of defining genre, as a result of which it ceases to apply only to the local occasion of rhetorical action. Noting that Bitzer observes "that [rhetorical] situations recur ... prompting comparable responses" or "recurring forms" or traditions, she argues that Bitzer points the way towards genre and hence away from the local and occasional (p. 151). Exigence is then conceived as the "core of [rhetorical] situation" (p. 157); it is a social construal of the complex of "objects, events, interests, and purposes that ... makes [it] an objectified social need" (p. 157). It is "neither a cause of rhetorical action nor an intention" (p. 158), but a motive, and is central to "joint action" (p. 158). Drawing on Miller's work in this regard some two decades later, Peter Medway (2002) makes recurrent exigence a test of generic membership: "genres remove the need to treat each exigence as a distinct problem that requires the time and effort of fresh invention for its solution. [...] a more or less completely worked out textual response is available for re-use" (p. 125). Bawarshi and Reiff (2010) agree, noting of Miller's account that her use of an ethnomethodological approach allows her "to locate genres in the environments of their use, as well as to describe the actions genres help individuals produce in these environments": "Part of the action that genres perform is the reproduction of the situations to which they respond" (pp. 69-70). Yet, while 
the "reproduction of the situations to which they respond" construes situation following Bitzer's suggestion regarding recurrence, the following use of the term shows an ambiguity that requires resolution:

Rhetorical situation [presents] an actual or potential exigence which can be completely or partially removed if discourse, introduced into the situation, can so constrain human decision or action as to bring about the significant modification of the exigence. (Bitzer, 1968, p. 6)

The former use is required by the ethnomethodological procedure of generalizable descriptions. Here the exigence is "reproduced." The latter use refers to rhetoric in practice: the situation is changed, or indeed removed. Is exigence definitional of the genre, as Miller requires, or does it describe the occasion of its use? Is it consolidated by its recurrence, or is it changed in its very occurrence?

We might resolve the question by suggesting that the problem arises in the same way as the tension between the diachronic and the synchronic dimensions of genre: in this case, exigence has some notional permanence intrinsic to the originating motive of the genre, while in practice the genre may be modified by the history of its uses. This tension is central to genre theory, which must handle both: in Schryer's (1993) formulation, a genre is "stabilized-for-now or stabilizedenough" (p. 200) but not set in concrete (cf. the extended discussion of change and stability in Miller \& Shepherd, 2009). However, we could accept Schryer's account of the diachronic durability of genres without committing to the view that exigence is intrinsic to genre. Indeed, it is more often the case than not that in use, genres provide resources that can be combined with those of other genres: hybridity, appropriation, mixity, and adaptation are responses to the exigence of use, not to the supposed exigence that motivated the invention of one or another of the genres in play. Furthermore, if exigence were intrinsic to a genre, we would have to accept that genres are locked into specifiable contexts. But genres are frequently recontextualized, and in such cases, their function changes. Indeed, as John Frow (2006) writes (citing Thomas Beebee), "genres have no essence; they have historically changing use values" (p. 135). Once changing use is brought into the picture, it must alter our account of function.

My focus on recontextualization follows Jacques Derrida's (1980) account of the "law of genre," which is not that we must not mix genres, but that we cannot not mix genres. To suppose that genres remained pure would be to imply that acts of discourse belong to a genre, that genres saturate their texts, and that their use throughout their histories does not affect their constitution or their uptake. On the contrary, Derrida argues, any act of discourse is altered by its context, and that context is infinitely mobile-and mixed. "Context" here may well be co-extensive with 
Volume 30, 2020

http://journals.sfu.ca/cjsdw

rhetorical situation. Note that the focus is on acts of discourse- not far from "action," and not antipragmatic or formalistic, which are charges often levelled against Derrida.

In this connection, I note that Miller (2017) acknowledges the distinction between "the situation or setting, the rhetorical exigence or function being served, and the way(s) that genres are taken up (or not)" (p. 23). Indeed, she distinguishes between exigence and purpose:

Both purpose and exigence are ways of addressing the question "why?" but they provide different kinds of answers. Purpose poses the question from an actor's point of view: why are you doing this? What is your aim or goal? ... exigence, or ... function, poses the question from a system's point of view: what does it achieve ... for the stability and viability of the rest of the system? (Miller, 2015, p. 175)

"The recurrent exigence of a genre is ... a matter ... of shared social recognitions," writes Miller (p. 175); this is convention. By contrast, the actor has a purpose; what she achieves may not be conventional at all. According to Miller in this passage, exigence is restricted to the genre, whereas my use of the term will be restricted to the occasion of the implementation of rhetorical decisions in order to intervene in social affairs. This suits the account I (2012) have given of a contested rhetorical situation; it also suits the account I give of uptake, although I insist that uptake is less a matter of subjective purpose than it is governed dynamically by the changing conditions of play. For that reason, it is more appropriate to rhetoric - the art, and the study, of discourse in practice-than is a reliance on systems.

I point out that Miller's distinction between purpose and exigence relies on one very like that of langue and parole. It presupposes that genres exist in a system. If this were a single system, one would have to suppose a closed set of genres based on the principle of difference which, like that of langue, holds each unit of the system in a functional, contrastive position distinct from that of all the others. ${ }^{8}$ Elsewhere, however, Miller (1984) makes it clear that "the set of genres is an open class" (p. 153). We would do well to respect Saussure's methodological stricture regarding this point: to isolate a "system" relies on taking a synchronic sampling. But the systematization of the sample interrupts diachrony, taking no account of what Bakhtin calls "living speech": what we call the "system" is continually changing with the use of its elements. ${ }^{9}$ Again we may cite Miller herself: "new members evolv[e], old ones [decay]" (Miller, 1984, p. 153). It is not that use draws on a pre-existent system, but that the (linguistic) "system" is an artefact of the formalizing devices developed by linguistics. Nevertheless, I enter an important caveat: as John Frow (2006) writes,

\footnotetext{
${ }^{8}$ Evidently the genres in use in particular settings-institutional or professional, for example-may well form local systems. See the work of Charles Bazerman (e.g., Bazerman, 1994).

${ }^{9}$ Derrida's argument rests on his sustained critique of the very distinction between system and use, which probes much further than the points I raise here (see Derrida, 1976).
} 
http://journals.sfu.ca/cjsdw

"genre norms are shared and shareable, and are built into more or less durable infrastructures" (p. 102). I shall return to the questions raised by the dichotomy of system and use in my concluding remarks.

\section{The Place of Rhetorical Action}

Is there a "system of genres" presupposing a "system of exigences"? To suppose that there were would be to rely on the assumptions structuralist social science adapted from linguistics. I reject the structuralist position insofar as it projects an overarching cultural or social system. Nevertheless, local and provisional systems are a different matter: they may correspond to Bakhtinian "spheres of activity" which assign places of speech and the manner of using them appropriately, and to Wittgensteinian "forms of life" adduced by Miller (1984, p. 159). We have already encountered an example in the secondary school adduced by Tumarkin (2018). Such sphere, and the places and functions they assign to the utterances deployed in them, may be more or less formalized, more or less regulated, but we may assume that they are both disparate and highly specific. A "recognized social need" (used to define exigence) must suppose this disparity and this specificity.

In previous work, I have made use of the term jurisdiction to capture the idea of a social sphere that regulates discourse. Then, I attributed this usage to Jean-François Lyotard (1983), but I now question this attribution. More accurately, it is an extrapolation from Lyotard's discussion of the limits of the law: at paragraph 215 of Le Différend, he asks how we could assess the legitimacy of a judgment passed under some law. The question arises because, as he argues, there is no overarching genre that could subsume the work performed by the diversity of genres; this is because there is no unified universe of discourse. He holds that each such genre has its own "tribunal" (court) to judge its truth or its success, to empower it, and to assess the limits of that power, as well as to admit the possible uptakes to any utterance that relies on that genre. In other words, the "tribunal" administers the "law" of that genre. If there is no "supreme" court,10 then the legitimacy of the judgments passed by a court cannot be founded in those of another court, let alone in a universal law. It is established by its jurisdiction, itself set out, alongside those of other courts, by the constitution. A jurisdiction is the arena of responsibility of a court; it states which court can hear what kinds of cases. The jurisdiction-or rather, the relation among jurisdictions-constrains and enables the work of the judges in each court, and something similar holds for areas of social responsibility and administration-ministries, for example-not governed strictly by

\footnotetext{
${ }^{10}$ It is clear that Lyotard uses this adjective to refer to a putative court that would rule on the rulings of all courts; he is not referring to the local arrangements of the U.S. judicial system.
} 
judicial conventions. This being the case, it seems reasonable to invoke the notion of a jurisdiction to serve as a metaphor in genre studies, without this running the risk of universalizing the rules (there is no constitution that oversees all constitutions). ${ }^{11}$ We can think of professions and institutions as working in this way; the academic disciplines do so, as do the universities that structure their relations and their areas of responsibility.

We can see a similar idea in more recent work by Miller (2017), where she uses the vocabulary of "domains" and "communities of use" in her discussion of the emergence of new genres. She delineates four categories of "domains in which genres operate" (p. 25). Her preliminary classification "relies on degrees of regulation" and is intended to account for "patterns and mechanisms" of the emergence and evolution of genres (pp.23-24). The four categories are: commercial genres, administered genres, institutional genres, and vernacular genres. The domain of "commercial" genres is governed by the "laws" of supply and demand. The "administered genres" are formalized under an authority that can "impose or require certain ways of doing things" (p. 23). The "institutional genres" are found in "[institutions] with strong conventions and sanctions" (p. 24) and are "held in place ... by the power of tradition, social status, and mutual expectation" (p. 24). The fourth category consists of the "vernacular genres" that "emerge and survive when a community finds a configuration of features that satisfies or pleases those who interact together, addressing some communally recognized exigence" (p. 25). Here, exigence must be intrinsic, as it has the status of an origin: the "communally recognized exigence" precedes the "emergence and survival" of the genre. There are "few institutional or administrative constraints" (p. 24) in this fourth type: they are assessed and regulated in the court of public opinion, which can also impose sanctions on malpractice. Note that the vocabulary of exigence- "needs," "desires," "satisfaction," and "pleasure"-persists for the vernacular genres, but it is not clear that "conventions" and "the power of tradition" would not do just as well. What we mean by "culture" is the intergenerational teaching and learning of such things. The formation of "communities" depends on mechanisms that achieve this. How conventions and traditions are changed is the interesting question; the processes of change are relatively fast or slow depending on the sphere of activity and the degree and source of regulation. Frow (2006) quotes Rick Altman in this regard: "genres appear to be initiated, stabilised and protected by a series of institutions essential to the very existence of genres" (p. 102), but Altman's focus is the film industry and the generalization may not hold as widely as he implies.

It seems to me that both domains and spheres lack a dimension that we need if we are to account for the forces that give a genre its place and keep it there, or allow that place to expand, and

\footnotetext{
${ }^{11}$ I am struck by the fact that, without lending it particular theoretical weight, Miller uses the term jurisdic-
} tion (Miller, 2003, p. 186). 
that give that genre a function to perform in relation to other functions. Jurisdiction does this job. I prefer it to exigence, because it doesn't seek the origins of a genre so much as the process of legitimation of a genre; this notion is particularly useful when we think about the delegitimizing powers of institutional gatekeepers, and the challenges posed to audiences by radical artistic practices. Moreover, it brings back into play the reviled notion of the "law" of genre which I think we need to readmit into our discussions: the laws of a genre are just its conventions and habits, and sometimes-only sometimes - its formal regulation. They both constrain and enable the inventiveness of its practitioners.

If a jurisdiction makes a place for a genre in the general economy of the genres it oversees, we could say that a ceremony admits a speaker or writer into a rhetorical situation that calls for that genre. I have used this notion of a ceremony in "Anyone for Tennis?" (Freadman, 1987/1994) and again in "Uptake" (Freadman, 2002), where I conflate it-I now think unhelpfully-with jurisdiction. A ceremony is a ritualized sequence of speech acts, or brief genres, in a more or less formalized time and space, enacted to fit persons to effect a specified action. Let us take as an example an invited lecture in a university. A speaker arrives at the lectern and asks for the attention of the audience; she introduces herself as the master of ceremonies, and in Australia she acknowledges that we are conducting our business on land traditionally owned by an Indigenous nation. She then calls on another speaker to introduce the guest speaker; this second speaker offers a welcome, introduces the topic, and invites the audience to join her in inviting the lecturer to take her place at the lectern. The audience does so with applause. After the lecture, the MC conducts a question and answer session, then closes proceedings with thanks. This ceremony is matched for a printed book, where all the things that Gérard Genette (1997) calls the "paratext" fulfil a similar function. This is not a mere list, but a sequence of textual objects or moments, placed so as to induct the reader into the act of reading: the book cover on which are printed the title of the book and the name of the author, the fly leaf on which are printed the place and date of publication, the copyright, the name of the publisher, and other information concerning the physical object, including its place in a library catalogue system. Inside, we find again the title and the name of the author, a table of contents aligned with page numbers, then inside again, preceding the text proper, we find dedications, a preface, an introduction, and acknowledgements (cf. Frow, 2006, p. 105).

In both these examples, the ceremony fits both the audience and the speaker or writer to do their jobs. The place and time are made ready and suitable: they are the concrete realization of the rhetorical situation. This must also be brought to a close: an electronic book may ask the reader to evaluate what she has read, while a printed book may show endorsements or laudatory comments from reviews. This is the place for applause for a lecture or other live performance, 
and informal evaluation will no doubt follow that.

Ceremonies are set by ancillary protocols attached to jurisdictions. To take the example of Grand Slam tennis, the jurisdiction is governed by the International Tennis Federation, while the ceremony is set by the local organizers in conformity with the requirements of play. As in the case of the invited speaker, the point of the ceremony is to bring the audience and the actors together in one place and train their attention on a common object. In courtroom dramas, the clerk of the court calls for "all to rise" at the entrance of the judge, and the judge inaugurates the formal proceedings; the beginning of sporting matches is marked with sirens or other auditory signals calling for the attention of the public, before the referees or umpires take up their places and play begins with a ritualized sequence of moves; a group meets at a bar, one member asks for orders, returns with the drinks, and then the serious business gets underway. A more formal example than this last would be a committee meeting, where the chair brings the meeting to order, reads the agenda, and embarks on the first item of business. A family dinner-table laid, family members at their assigned or habitual places-might start with the setting aside of toys, games, or phones. What is important about the ceremony in all cases is that it is responsible for the implementation of an instance of a genre, or its admixture with other genres, on occasion.

Let us take a lead from Quintilian, the great teacher of rhetoric. Quintilian instructs us that the skilled speaker must learn from as wide a range of both the rhetorical and the poetic genres as possible. "Reading and listening to the best writers and orators" (Quintilian, trans. 1922/1993, Book X, chapter 1, p. 7) provides the copia of the orator, the wealth of resources on which her or his invention can draw. Quintilian introduces his exposition of this precept with an allusion to sport:

Our present task is to consider how our athlete who has learnt all the technique of his art from his trainer, is to be prepared by actual practice for the contests in which he has to engage. [...] There can [...] be no doubt that he must accumulate a certain store of resources, to be employed whenever they may be required. (Quintilian, trans. 1922/1993, p. 7)

He then proceeds to outline what can be learned from different genres: the reading of poetry can be of great service for the rhythmical value of words, and for the use of figures of speech; the diction of comedy may be misleading, whereas history provides material for analogies between situations known from the past and the case at hand. Nevertheless, history must be used circumspectly, otherwise it would lead to excessive use of digression. And, given the vocation of Quintilian and his school, the speeches of great orators should be studied. "For in everything we teach examples are more effective even than the rules. [...] And the reason is this, that the professor of 
rhetoric lays down the rules, while the orator gives a practical demonstration" (p. 11). Anything acquired from this range of reading and listening must be laid down for later use; but it is not properly learnt if it merely results in an "assembly of a disorderly crowd of words" (p. 7). Changing his simile, he tells us what it is to integrate that "store of resources":

We must return to what we have read and reconsider it with care, while, just as we do not swallow our food till we have chewed it and reduced it almost to a state of liquefaction to assist the process of digestion, so what we read must not be committed to the memory for subsequent imitation while it is still in a crude state, but must be softened and, if I may use the phrase, reduced to a pulp by frequent reperusal. (p. 13)

Quintilian was known as "the Schoolmaster": he taught rhetoric to boys who were destined to take their place in the public life of Rome. The range of generic places they might speak in was strictly set down by the jurisdictions of the senate. When he considers the genres they will have to use in those roles (the famous three genres: forensic, epideictic, and deliberative), he classifies them according to their place, or their function. Jurisdiction helps us to understand what place is in this sense. On the other hand, Quintilian is concerned in this passage with practice. Practice entails agency. The important question for the schoolmaster is how the passive, receptive learner becomes an agent. This is what happens between the jurisdiction and the occasion of speech, through the study of a wide range of examples. The inventive agent will take her place at the lectern, or on the shelves of a library, called to speak, or write, in a rhetorical situation, when a ceremony invites her to perform her role and urges the audience to take it up.

\section{Concluding Remarks}

My accounts of jurisdiction and ceremony have distinguished the two tasks given to exigence in much rhetorical genre theory, in accounting for the function of the genre, and in accounting for the effects of its situated practice. The first task is the place that calls for a specific genre; it may provide the opportunity for a new genre, or the adaptation of an existing genre. This is place construed as function. Under my account, the function of a genre is delineated under a more or less formal jurisdiction. The second task is achieved by the ceremony, bringing the speaker or writer into a place and time defined as an occasion. This distinction allows us to account for the different factors at play in each. The function of a genre is defined by its place in the sphere of activity: what is it that other genres cannot, or do not, do? The situated practice shows us discourse at work, taking stock of the particularities of the audience, its needs and requirements, calculating uptake in order to achieve its purpose, and drawing potentially on a range of genres to do so.

Much work in Rhetorical Genre Studies assumes a match between situation construed as place, 
and situation construed as occasion, but I have argued that this assumption is seldom borne out in practice. The relation between genre and rhetorical occasion is neither one of replication, nor that of a generative motive. It is diachronic in the sense that function-place and genre-are generalizations over observed occasions, where it is clear that past usage builds up a stock of resources that can be called on for further occasions. Two questions arise: (i) what is a typified situation that can be said to call for a genre? And, given my arguments against the model of langue and parole, (ii) what is the relation between a type and its occurrence? I shall sketch answers to these questions based on a conceptual framework distinct from that of rhetoric, that is, general semiotics.

(i) As a general semiotician - as distinct from a linguist, a literary scholar, or indeed a rhetorician-I am drawn to investigate the notion of the semiotic as used in Miller's (1984) work: "rhetorical situation is not material and objective, but a social construct, or semiotic structure" (p. 157). This usage corresponds to M. A. K. Halliday's usage, in which it refers to the social construction of meaning, as well as to the reduction of the semiotic by Charles Morris to group the branches of linguistics into syntax, semantics, and pragmatics: "the semantic values of a string of words and their syntactic relationships in a sentence acquire meaning," where "meaning" is construed as their "pragmatic value as action" (Miller, 1984, p. 159). But in my usage, semiotic refers to the full panoply of signs, not exclusively linguistic signs. ${ }^{12}$ In the case of performances-lectures, sporting marches, theatre, music, etc.-the space is designed to designate and facilitate the roles of performer and audience. The speaker in a lecture stands, the audience remains seated. Various kinds of printed material and images are distributed or projected. Time, too, is organized semiotically, by clocks and various forms of institutional scheduling; importantly, like the space, the time of the performance is separated out from the time of other events from which it is reciprocally distinguished by the principle of difference. It is not clear to me, then, why the genre is distinct from the situation in which it takes place: for a semiotician, the genre just consists of all of these things. It is only by singling out language that situation seems to be made of a different kind of stuff. 13

Of course, Bitzer (1968) does not mean situation in this sense; he means a problem requiring (inviting, obliging, dictating) rhetorical intervention for its solution. However, no matter how complex the problem - a political debate, a humanitarian crisis, a crime, or a question-it is never not represented, it is never a-semiotic. We are returned to Bakhtin's responsive chain, to the

\footnotetext{
${ }^{12}$ It is interesting to me that the term multi-modality has been introduced to deal precisely with this reduction to language, and the resulting erasure of the semiotic in the broader sense.

${ }^{13}$ The issues are different if the question is formulated in terms of the internal structure and the external structure of the "text," with the separating edge functioning as a "frame" (see Frow, 2006, pp. 103).
} 
tennis match, or to Charles Peirce's notion of infinite semiosis in which any sign interprets and re-represents the object of a previous sign, and in its turn is taken up in a subsequent sign. Uptake is a fundamentally semiotic concept.

(ii) Langue/parole; system and use; a genre and its instantiation: these are all problematic dichotomies. In order to propose a solution to the problem, I shall draw on Peirce's semiotics. In his work of 1903, we find a formulation that appears to rely on a similar dichotomy: "a 'Legisign' is a law that is a sign ... it signifies through an instance of its application, which may be termed a Replica of it" (Peirce, 1998, p. 291). However, a year later, we find an alternative terminology: this is type and token (terms that have passed into regular use in logic). ${ }^{14}$ Type is adopted from typography and refers to a standardized, or conventional "significant form," whereas a token "is a single event ... or a single object or thing ... such event or thing being significant only as occurring just when and where it does" (Peirce, 1778, Vol. 4, para. 537). In this reformulation, the relation between the type and its token is not merely one of replication: a token, Peirce writes, shall be a sign of its type (emphasis added). This requirement brings into play the entire mechanism of infinite semiosis: that the interpretant represents the same object as the sign it interprets, while at the same time representing it differently. Signs are what they are in virtue of mediating between the current state of knowledge and its future modification; semiosis is dynamic, it is a mechanism of change. This applies equally to genres: they mediate between the current state of practice and the requirements of new exigences.

Note that the type/token relation as theorized by Peirce is complementary with the process described by Miller (following Schutz) whereby we take some unfamiliar or new occurrence as some type (Miller, 1984, pp. 156-157): the type interprets the token. In this case, the process of interpretation reduces variation to similarity, whereas, working in the opposite direction, the new case varies the type by extending its scope, modifying the truths it purports to purvey, changing its significance. This is so with the application of legal precedents-and of axioms or maxims, proverbs, or the sayings of folk wisdom. Whatever the social conditions invoked to account for the protection of generic norms or their destabilization-institutional, jurisdictional, regulatory-we need also to assume a mechanism such as infinite semiosis to account for the combination of inertia and instability observable in the practice of genres. The point where they combine and diverge is where we find agency. My argument, then, concludes with the primacy of the processes of change, and suggests that the collections we call systems represent the local and provisional arrest of these processes by the inertia of habitual practice. Yet we need that inertia in order to account for the social recognition of needs and functions.

\footnotetext{
14 I draw on my discussion of this matter in Freadman (2004).
} 
http://journals.sfu.ca/cjsdw

Genre defined as a collection of resources available to be drawn on in a variety of situations; genre defined by its purported originating exigence. In the former case, agency is performance, the site of strategic and tactical choice exercised on the basis of training or experience, or simply of street-smarts; in the latter, the agent is subjected to the genre, a passive occupant of the subject-position(s) it sets out. The ambivalence between these two accounts is resolved if, and only if, we assume a deep correlation between the two on the model of system and use, langue and parole, where the former so constrains the latter as to preclude change. Yet everywhere, in all kinds of cases, we observe change in genre, we observe restriction and contraction in the situations in which a genre may appear, and the use of unfamiliar genres in situations where we might have expected others. Habits are broken or adapted, inert only when the conditions that maintain them remain constant. Contexts shift.

This alternative is not merely a tension or an ambivalence; it arises from a clash between the objectives of genre theory and those of genre studies: the abstraction of genre must tend to reify it, while the study of genres in practice tends to display their mobility. Notwithstanding my avowal that this essay is an exercise in theory, on the grounds that it focuses on concepts and their application, and on the use of concrete examples as illustrations, I find that my whole argument has leaned to the side of the rhetorical practice of genre. It is this that has led me back to the issue of system and use; in place of a self-reproducing system, I presume the model of precedent and application, where each interprets the other. The string of precedents is read through this history of interpretation, and the feedback loop that represents them otherwise.

The responsive chain with its automatisms and its struggles; uptake, with its dispersal of agency over (at least) two partners; infinite semiosis, with its account of the gradual, or abrupt, modification of familiar representations and its capacity to alter the path of inquiry when it encounters what Peirce (1998) calls a "surprise." "Experience invariably teaches by surprise" (p. 195), he writes; "every inquiry ... takes its rise in the observation ... of some surprising phenomenon, some experience which either disappoints an expectation, or breaks in upon some habit of expectation" (pp. 440-441). If this is so of the practice of genres, it is also true of the genres that study genres.

\section{Acknowledgements}

This paper had its genesis in a series of workshops conducted with Carolyn Miller in Melbourne, and the conversations we had following the sessions. It is also amply nourished by a course I taught with Sune Auken in Copenhagen, where I first developed the critique I present here. I thank both colleagues, as well as John Frow, for their comments on earlier drafts of this paper. 
http://journals.sfu.ca/cjsdw

\section{References}

Bakhtin, M. M. (1986). The problem of speech genres (V. W. McGee, Trans.). In C. Emerson \& M. Holquist (Eds.), Speech genres and other late essays (pp. 60-102). Austin: University of Texas Press.

Bawarshi, A. (2003). Genre and the invention of the writer: Reconsidering the place of invention in composition. Logan: Utah State University Press.

Bawarshi, A. (2015). Accounting for genre performances: Why uptake matters. In N. Artemeva \& A. Freedman (Eds.), Genre studies around the globe: Beyond the three traditions (pp. 186206). Edmonton, AB: Inkshed.

Bawarshi, A., \& Reiff, M. J. (2010). Genre: An introduction to history, theory, research, and pedagogy. West Lafayette, IN: Parlor Press. Retrieved from https://wac.colostate.edu/books/referenceguides/bawarshi-reiff/

Bazerman, C. (1994). Systems of genres and the enactment of social intentions. In A. Freedman \& P. Medway (Eds.), Genre and the new rhetoric (pp. 79-101). London, UK: Taylor \& Francis.

Bitzer, L. F. (1968). The rhetorical situation. Philosophy and Rhetoric, 1, 1-14.

Derrida, J. (1976). Of grammatology (G. C. Spivak, Trans.). Baltimore, MD: John Hopkins University Press.

Derrida, J. (1980). The law of genre (A. Ronell, Trans.). Critical Inquiry, 7(1), 55-81.

Elliott, H. (2018, June). “Axiomatic” by Maria Tumarkin. [Review of the book Axiomatic, by M. Tumarkin]. The Monthly, June 2018. Retrieved from https://www.themonthly.com.au/issue/2018/june/1527775200/helen-elliott/axiomatic-maria-tumarkin\#mtr

Freadman, A. (1994). Anyone for tennis? In A. Freedman \& P. Medway (Eds.), Genre and the new rhetoric (pp. 43-66). London, UK: Taylor \& Francis. (Reprinted from The place of genre in learning: Recent debates, pp. 91-124, by I. Reid, Ed., 1987, Geelong, Australia: Centre for Studies in Literary Education, Deakin University)

Freadman, A. (2002). Uptake. In R. Coe, L. Lingard, \& T. Teslenko (Eds.), The rhetoric and ideology of genre: Strategies for stability and change (pp. 39-53). Cresskill, NJ: Hampton Press.

Freadman, A. (2004). The machinery of talk: Charles Peirce and the sign hypothesis. Stanford, CA: Stanford University Press.

Freadman, A. (2012). The traps and trappings of genre theory. Applied Linguistics, 33(5), 544563. doi:10.1093/applin/ams050

Freadman, A. (2014). Where is the subject? Rhetorical genre theory and the question of the writer. Journal of Academic Language \& Learning, 8(3), A1-A11.

Frow, J. (2006). Genre. New York, NY: Routledge. 
Volume 30, 2020

http://journals.sfu.ca/cjsdw

Fuller, G., \& Lee, A. (2002). Assembling a generic subject. In R. Coe, L. Lingard, \& T. Teslenko (Eds.), The rhetoric and ideology of genre: Strategies for stability and change (pp. 207-224). Cresskill, NJ: Hampton Press.

Genette, G. (1997). Paratexts: Thresholds of interpretation. Cambridge, UK: Cambridge University Press.

Goffman, E. (1959). The presentation of self in everyday life. Garden City, NY: Doubleday.

Irvine, A. D., \& Deutsch, H. (2016). Russell's paradox. In E. N. Zalta (Ed.), The Stanford Encyclopedia of Philosophy Archive (Winter 2016 ed.). Retrieved fromhttps://plato.stanford.edu/archives/win2016/entries/russell-paradox/

Lyotard, J.-F. (1983). Le différend. Paris, France: Les Éditions de Minuit.

Medway, P. (2002). Fuzzy genres and community identities: The case of architecture students' sketchbooks. In R. Coe, L. Lingard, \& T. Teslenko (Eds.), The rhetoric and ideology of genre: Strategies for stability and change (pp. 123-153). Cresskill, NJ: Hampton Press.

Miller, C. R. (1984). Genre as social action. Quarterly Journal of Speech, 70(2), 151-167. doi:10.1080/00335638409383686

Miller, C. R. (2001). Writing in a culture of simulation. In P. Coppock (Ed.), The semiotics of writing: Transdisciplinary perspectives on the technology of writing (pp. 253-280). Turnhout, Belgium: Brepols.

Miller, C. R. (2003). The presumptions of expertise: The role of ethos in risk analysis. Configurations, 11(2): 163-202. doi:10.1353/con.2004.0022

Miller, C. R. (2007). What can automation tell us about agency? Rhetoric Society Quarterly, 37(2), 137-157. doi: 10.1080/02773940601021197

Miller, C. R. (2015). Genre change and evolution. In N. Artemeva \& A. Freedman (Eds.), Genre studies around the globe: Beyond the three traditions (pp. 154-185). Edmonton, AB: Inkshed.

Miller, C. R. (2017). “Where do genres come from?”. In C. R. Miller \& A. R. Kelly (Eds.), Emerging genres in new media environments (pp. 1-34). Cham, Switzerland: Palgrave Macmillan. doi:10.1007/978-3-319-40295-6_1

Miller, C. R., \& Shepherd, D. (2009). Questions for genre theory from the blogosphere. In J. Giltrow \& D. Stein (Eds.), Genres in the Internet: Issues in the theory of genre (pp. 263-290). Amsterdam, The Netherlands: John Benjamins.

Miller, N. K. (1988). Subject to change: Reading feminist writing. New York, NY: Columbia University Press.

Paré, A. (2002). Genre and identity: Individuals, institution, and ideology. In R. Coe, L. Lingard, \& T. Teslenko (Eds.), The rhetoric and ideology of genre: Strategies for stability and change (pp. 57-71). Cresskill, NJ: Hampton Press. 
http://journals.sfu.ca/cjsdw

Peirce, C. S. (1998). The essential Peirce: Selected philosophical writing, Volume 2 (1893-1913)

(The Peirce Edition Project, Ed.). Bloomington: Indiana University Press.

Peirce, C. S. (1778). Collected Papers of Charles Sanders Peirce (C. Hartshorn \& P. Weiss, Eds., Vol. 4). Cambridge, MA: Harvard University Press.

Quintilian. (1993). Institutio Oratoria (H. E. Butler, Trans., 1922). Cambridge, MA: Harvard University Press.

Schryer, C. F. (1993). Records as genre. Written Communication, 10(2), 200-234. doi:10.1177/0741088393010002003

Schryer, C. F. (2018). Genre time/space: Chronotopic strategies in the experimental article. In C. R. Miller \& A. J. Devitt (Eds.), Landmark essays on rhetorical genre studies (pp. 154-161). London, UK: Routledge.

Tumarkin, M. (2018). Axiomatic. Melbourne, Australia: Brow Books.

Willett, C., Anderson, A., \& Meyers, D. (2015). Feminist perspectives on the self. In E. N. Zalta (Ed.), The Stanford Encyclopedia of Philosophy Archive (Winter 2016 ed.). Retrieved from https://plato.stanford.edu/archives/win2016/entries/feminism-self/ 